\title{
Deriving "potential target values" of PCDD/F in animal feed: the role of livestock at the interface between feed and food chain
}

\author{
Maria José Abud Clariget ${ }^{1}$ Janine Kowalczyk ${ }^{2} \cdot$ Birgit Wobst $^{2}$ (1)
}

Received: 11 May 2021 / Revised: 13 October 2021 / Accepted: 21 October 2021 / Published online: 17 November 2021

(c) The Author(s) 2021

\begin{abstract}
Linking derivation of potential target values of PCDD/Fs in animal feed with risk assessment for consumer protection is a challenge when tolerable weekly intake (TWI) and transfer factors from feed to food are considered. Generally, maximum values for feed and food are set separately without considering the feed and the food producing animal as an important factor along the food chain from farm to fork. Levels of contaminants in feed can accumulate in animals and their products effect consumers at the end of the food chain. Hence, the process of setting legal maximum levels of contaminants should account for transfer from feed consumed by food producing animals into animal products for human consumption. Here, we calculated potential target values of $\mathrm{PCDD} / \mathrm{F}$ in feed to ensure that animal products such as milk from dairy cows, eggs from laying hens and pork and pork products from fattening pigs are safe for human consumption. In our approach, we calculated potential target values of PCDD/Fs in animal feed using transfer factors for PCDD/F-TEQs from feed to milk fat, eggs fat, and fat in pork and pork products, taking into account the tolerable weekly intake derived by European Food Safety Authority. We assumed equal proportions of WHO-PCDD/F-TEQ and WHO-PCB-TEQ in feed. Potential target values of PCDD/F in feed are expressed as the quantity of toxicologically evaluated PCDD/Fs, expressed in WHO toxic equivalents $\left(\mathrm{WHO}_{2005}-\mathrm{PCDD} / \mathrm{F}-\mathrm{TEQ}\right)$ per kg feed with $12 \%$ moisture. In the current approach, derived values would be 10-54 times lower than the current legal maximum level of $0.75 \mathrm{ng} \mathrm{WHO}_{2005}-\mathrm{PCDD} / \mathrm{F}-\mathrm{TEQ}$ per $\mathrm{kg}$ feed (12\% moisture), according to Directive 2002/32/EC as amended.
\end{abstract}

Keywords Livestock · Feed and food chain · Dioxins $\cdot \mathrm{WHO}_{2005}$-PCDD/F-TEQ $\cdot$ Transfer factor $\cdot$ Human risk assessment

\section{Introduction}

Polychlorinated dibenzodioxins and -furans (PCDD/Fs), commonly termed "dioxins", and dioxin-like polychlorinated biphenyls (DL-PCBs) are two- or three-ring structures that can be chlorinated to varying degrees. DL-PCBs can have up to ten chlorine atoms substituting hydrogen atoms, whereas PCDD/Fs can have up to eight (WHO 2010). $\mathrm{PCDD} /$ Fs refer to two groups of tricyclic planar compounds

Birgit Wobst

birgit.wobst@bfr.bund.de

1 Food Safety and Quality Division, Animal Feed Department of the Ministry of Livestock Agriculture and Fisheries, General Direction of Agricultural Services, Montevideo, Uruguay

2 Department Safety in the Food Chain, German Federal Institute for Risk Assessment, Max-Dohrn-Straße 8-10, 10589 Berlin, Germany
(PCDDs and PCDFs) for which, depending on the number of chlorine atoms and their positions at the rings, a total of up to 75 PCDDs and 135 PCDFs so called 'congeners' can occur. The 17 compounds, which are chlorinated in the 2, 3, 7,8 position, share the same mode of action, are highly toxic and at the same time persistent. Thus, they accumulate in the adipose tissue of animals and humans and are therefore considered relevant for human (and animal) health. For risk assessment purposes, toxicity equivalency (TEQ) was developed to describe the cumulative toxicity of complex mixtures of these compounds. The most toxic congener, 2, 3, 7, 8 -TCDD, is assigned a value of 1 . The toxicity equivalency factors (TEFs) for the individual congeners are between 0 and 1 , indicating the magnitude of their toxicity in relation to 2, 3, 7, 8-TCDD. The TEF values including DL-PCB were first proposed by the WHO in 1997 (WHO $_{1998}$-TEQs; van den Berg et al. 1998) and were re-evaluated by a WHO working group in 2005 ( $^{2} \mathrm{HO}_{2005}$-TEQs; van den Berg et al. 2006, in the following referred as " $\mathrm{WHO}_{2005}$-TEQ"). 
The amount of a congener in a sample is multiplied by the respective TEF. The sum of all resulting products is a measure of the dioxin-related toxicity of the congeners in the sample, the so called WHO-TEQs.

PCDD/Fs and PCBs are very stable against chemical and microbiological degradation and therefore persistent in the environment from where they are transferred into the food chain. Hence, food is considered to be the major source of human exposure to PCDD/Fs and PCBs, with the exception of specific cases of accidental or occupational exposure (Travis and Hattemer-Frey 1991; Fries 1995; Windal et al. 2010; EFSA 2012a, 2018). In contrast to PCBs, PCDD/Fs have never been produced on an industrial scale and have no technological use. They are formed unintentionally in a number of industrial and thermal processes as unwanted and often unavoidable impurities or reaction by-products (EFSA 2012a, 2018).

Because of their lipophilic properties, these substances preferentially accumulate in adipose tissues. Thus, foods of animal origin showed highest contribution to human exposure to PCDD/Fs and DL-PCBs. In 2001, the Scientific Committee on Food (SCF) which was the predecessor of the European Food Safety Authority (EFSA), derived a tolerable weekly intake (TWI) of $14 \mathrm{pg} / \mathrm{kg}$ bw as health based guidance value (HBGV) for PCDD/Fs and DL-PCBs. In 2018, the Panel on Contaminants in the Food Chain (CONTAM) of EFSA, re-assessed the health risk posed by exposure to PCDD/Fs and DL-PCBs. The new EFSA-TWI of $2 \mathrm{pg} / \mathrm{kg}$ bw is seven times lower than the TWI of 2001. It is based essentially on a study conducted on young men, in whom exposure of PCDD/Fs and DL-PCBs on sperm quality and sperm count was examined (EFSA 2018). The CONTAM panel estimated the weekly intake of dioxins and DL-PCBs for various age groups based on the consumption and occurrence data in Europe. The panel concludes that exposure in European consumers exceed the new TWI considerably in all age groups (EFSA 2018).

Both, maximum levels in feed and food for PCDD/Fs and DL-PCBs are generally not set based on toxic effects. Derivation of maximum levels of contaminants in feed (and food) is often performed without consideration HBGVs. Consumption of food derived from food producing animals may lead to exposure exceeding the TWI (e.g. for dioxins/DLPCB) although feed was legislative compliant with European maximum levels according to Directive 2002/32/EC (2002). Moreover, such feed fed to livestock can cause food of animal origin that exceeds the legal maximum levels for food (according to Commission Regulation (EC) No. 1881/2006 as amended by Commission Regulation (EU) No 1259/2011 (e.g. Lorenzi et al. 2020; Spitaler et al. 2005). Consequently, substance transfer along the feed-to-food-chain and consideration of HBGV should be part of a practical approach when deriving maximum levels of undesirable substances in feed.
By doing so, the challenge is to find maximum levels which are both practically applicable hence avoiding feed waste, and protective for animals and consumers at the end of the food chain. (Very) low values might not be of practical use if either background levels are already at the same level or even higher and/or for analytical reasons e.g. if they could not be reproducibly determined. This might be the case when they are below or in the range of detection or quantification limits.

In this article, we demonstrate an approach that considers several steps in the food chain, regarding PCDD/Fs in feed which is consumed by food producing animals, transferred to food for human consumption. The calculation of such values-in our paper referred to as "potential target values" was exemplarily performed for PCDD/F $\mathrm{WHO}_{2005}$-TEQ in feed for dairy cows, fattening pigs, and laying hens. The aim was that consumption of milk from dairy cows, eggs from laying hens and pork and pork products from fattening pigs will not exceed EFSA's TWI for PCDD/F-DL-PCB. The quandary of the attempt should be part of a broader discussion.

\subsection{Objective}

The objective of this work is the derivation of potential target values of PCDD/Fs in feed for dairy cows, fattening pigs, and laying hens, using the new tolerable weekly intake (TWI) derived by EFSA (2018). The values are exemplarily derived for PCDD/Fs only (all congeners). Potential target values for DL-PCBs or $\mathrm{WHO}_{2005}$-PCDD/F-DL-PCB-TEQ were calculated separately for transfer into milk and results were compared. There is less literature reporting transfer factors for DL-PCBs at steady state conditions (Amutova et al. 2021; Lorenzi et al. 2020; VDI 2019). PCDD/F concentrations in the total feed ration should consider potential target values for farm animals that serve to protect these animals thereby ensuring that foods derived from them are safe for human consumption (VDI 2005, 2019). The derived potential target values in feed are indicated as the quantity of toxicologically evaluated $\mathrm{PCDD} / \mathrm{Fs}$, expressed in WHO toxic equivalents $\left(\mathrm{WHO}_{2005}-\mathrm{PCDD} / \mathrm{F}-\mathrm{TEQ}\right)$ per $\mathrm{kg}$ feed ( $88 \%$ dry matter and relative to a feed with $12 \%$ moisture).

\section{Material and methods}

\subsection{Calculation of transfer factors}

The calculation of transfer factors (TF) is presented in Table S1 Supplementary Material). Briefly, Lorenzi et al. (2020) reported concentration of PCDD/F-TEQ, DL-PCBTEQ and of PCDD/F + DL-PCB-TEQ after addition of defined concentrations of $\mathrm{PCDD} / \mathrm{F}$ und $\mathrm{PCB}$ congeners in feed. The reported transfer into milk (pg/g fat) at the end of 
the exposure period (day 49, steady state conditions) was divided by the concentration in feed (pg/g feed). Uptake from feed and excretion into milk is very variable between congeners. We accounted for this variation by using TEQ values for the sum of PCDD/F congeners. Likewise, TFs were calculated from the feeding study performed by Hoogenboom et al. (2015) using PCDD/F-TEQ and DLPCB-TEQ values in maize silage and reported concentration in milk at day 29 of exposure (Table S2, Supplementary Material). We used the mean TF of both studies for PTV calculation as described below.

To calculate PTV transfer from feed for laying hens into eggs, the study performed by Stephens et al. (1995) was identified as most appropriate. TFs for excretion of PCDD/F congeners were calculated similarly using concentrations given in feed (including soil, $\mathrm{pg} / \mathrm{g}$ ) and eggs (pg/g fat), applying $\mathrm{WHO}_{2005}$ TEF values (Table S3, Supplementary Material).

Finally, we calculated TFs for transfer from feed for fattening pigs into pork on information obtained from the study performed by Spitaler et al. (2005). Transfer into belly fat was calculated for PCDD/F TEQ based on two study groups receiving 0.75 and $2 \mathrm{pg} / \mathrm{g}$ feed, respectively. Lower concentrations in feed resulted in higher TFs (1.1 and 2.2, respectively). The higher value rounded to 2.0 was applied for PTV calculation (Table S4, Supplementary Material).

\subsection{Assumptions}

In order to link derivation of potential target values of PCDD/Fs in animal feed with risk assessment for consumer protection, the following assumptions were taken into account:

- Equal proportions of WHO-PCDD/F-TEQ and WHOPCB-TEQ in feed were assumed. As the TWI established by EFSA (2018) is of $2 \mathrm{pg} \mathrm{WHO}{ }_{2005}$-PCDD/F-PCB-TEQ/ $\mathrm{kg}$ bw/week, a "tolerable daily intake" (TDI ${ }^{1}$ ) of WHOTEQ is assumed to be $0.14 \mathrm{pg} / \mathrm{kg}$ body mass for PCDD/F (50\% of TWI on a daily base).

- Kinetics of the individual congeners are different resulting in different transfer rates from feed into food (e.g. congeners 2, 3, 7, 8-TCDD, 1, 2, 3, 7, 8-PeCDD and $2,3,4,7,8$-PeCDF account for as much as $71 \%$ of the total WHO-TEQ in cows' milk, $67 \%$ in pork and $62 \%$ in eggs as calculated from German Food Monitoring data

\footnotetext{
1 A TDI for $\mathrm{WHO}_{2005}$-PCDD/F-PCB-TEQ does not exist. The "TDI" value used in the calculation was taken from the TWI divided by 7 to obtain a reference value on the daily basis. Fifty percent of the values were used, assuming equal contribution of exposure of DL-PCB and PCDD/F.
}

2007-2011). We calculated potential target values in feed $\left(\mathrm{PTV}_{\mathrm{F}}\right)$ based on $\mathrm{WHO}_{2005}-\mathrm{PCDD} / \mathrm{F}$ TEQ.

- The TFs, defined as quotient of concentration in $\mathrm{pg} / \mathrm{g}$ fat in animal product under steady state conditions and concentration in $\mathrm{pg} / \mathrm{g}$ feed; dry matter, of the three $\mathrm{WHO}_{2005}-\mathrm{PCDD} / \mathrm{F}-\mathrm{TEQ}$ were:

- 3.3 to 5.6 from feed to milk fat (Hoogenboom et al. 2015; Lorenzi et al. 2020). ${ }^{2}$ A mean TF of 4.5 were taken forward for calculation of $\mathrm{PTV}_{\mathrm{F}}$.

- 1.9 from feed to eggs fat was taken for the calculation (Stephens et al. 1995, calculated as $\mathrm{WHO}_{2005}$-PCDD/F-TEQ).

- 1.1 to 2.2 from feed to fat in pork and pork products, depending on concentration of PCDD/F-TEQ in feed (Spitaler et al. 2005). The higher value of 2.2 (rounded 2) was taken forward for calculation (calculated as $\mathrm{WHO}_{2005}-\mathrm{PCDD} / \mathrm{F}-\mathrm{TEQ}$ ).

The most recent and appropriate studies were selected if they met the following criteria: a comprehensive description of the experimental setup, duration of exposure which showed steady state conditions, studies considering all 17 congeners and, and with species in questions with good productivity. We only used studies that allows us to calculate TFs based on PCDD/F-TEQ and-in the case of transfer into milk-additionally for DL-PCB-TEQ. The TF of $\mathrm{WHO}_{2005}$-DL-PCB-TEQ was 5.3 to 7.5 from feed to milk fat (Hoogenboom et al. 2015; Lorenzi et al. 2020). The mean transfer factor for the calculation of $\mathrm{PTV}_{\mathrm{F}}$ for DL-PCB was 6.4. It is generally accepted that food is the major source of exposure to PCDD/F for consumers, where milk fat accounts for $30 \%$, egg fat for $6 \%$ and fat from pork and pork products up to $5 \%$ of the total amount of WHO-TEQ main food group levels (Schwarzet al. 2014). A "daily fat consumption" per person per day of $40 \mathrm{~g}$ in milk of dairy cow, $3.8 \mathrm{~g}$ in eggs and $11.3 \mathrm{~g}$ from pork and pork products (Table 1) was used for calculation (Schwarz et al. 2012; Statista 2020). Based on all parameters described and considered (Table 1), potential target values of PCDD/Fs in feed were calculated in order to comply with the TWI derived by EFSA (2018).

\section{Results}

Concepts describing transfer from feed into animal products varies in literature. In our calculation, we selected studies that gave sufficient information on study design and

\footnotetext{
${ }^{2}$ Huwe and Smith (2005) reported comparable bioconcentration factors for transfer from contaminated mineral supplement in feed into milk from dairy cows of 5.5 and 5.9 at steady state.
} 
Table 1 Assumptions for calculation potential target values of undesirable substances in animal feed on the basis of EFSA's TWI

\begin{tabular}{ll}
\hline Parameter & Value \\
\hline Tolerable daily intake of dioxins & $0.14 \mathrm{pg} / \mathrm{kg}$ bw per day ${ }^{1}$ \\
Average human body weight & $70 \mathrm{~kg}$ \\
Percentage of PCDD/F intake with food: & \\
Milk & $30 \%(0.3 \text { decimal digit })^{2}$ \\
Egg & $6 \%(0.06 \text { decimal digit })^{2}$ \\
Meat (pork) & $5 \%(0.05 \text { decimal digit })^{2}$ \\
Average daily consumption of fat (FC): & \\
Milk fat & $40 \mathrm{~g}^{3}$ \\
Egg fat & $3.8 \mathrm{~g}^{3}$ \\
Pork fat (belly) & $11.3 \mathrm{~g}^{3,4}$ \\
Transfer factors: & \\
Feed-milk & 4.5 \\
Feed-egg & 1.9 \\
Feed-pork meat & 2.0 \\
\hline
\end{tabular}

Consumption of pork fat calculated from relation of pork to meat consumption in Germany 2018 (Statista 2020) and total fat consumption through meat (Schwarz et al. 2012)

${ }^{1}$ EFSA (2018)

${ }^{2}$ Schwarz et al. (2014)

${ }^{3}$ Schwarz et al. (2012)

${ }^{4}$ Statista (2020)

outcome in order to calculate TFs. Lorenzi et al. (2020) and Hoogenboom et al. (2015) calculated carry-over rates from the quotient of concentration in milk fat (pg/g fat) * fat yield $(\mathrm{g} / \mathrm{d})$ and the concentration in feed ( $\mathrm{pg} / \mathrm{kg}$ feed) $*$ feed intake $(\mathrm{g} / \mathrm{d})$. We use the term "transfer factor" as quotient from the concentration of PCDD/F-TEQ and DL-PCB-TEQ in milk fat and the concentration in feed at steady state conditions. Hence, fat yield and feed consumption as given in the respective studies are covered but are no direct parameters in our calculation of $\mathrm{PTV}_{\mathrm{F}}$. The same applies for the calculation of TF for animal feed into egg's fat and pork fat, respectively (Stephens et al. 1995; Spitaler et al. 2005). The term "transfer factor" is used throughout the manuscript and calculated to account for accumulation in fat over time. In the literature, some authors used "bio-concentration factor"
(BCF) with the same definition (e.g. Lorber et al. 2000; Huwe and Smith 2005) while others defined it differently (e.g. Amutova et al. 2021).

\subsection{General equation for the calculation of potential target values $\left(\right.$ PTV $_{\mathrm{F}}$ ) in feed}

Based on the described assumptions, tolerable levels $\mathrm{PTV}_{\mathrm{F}}$ of PCDD/F in animal feed were calculated using the following equations:

$\mathrm{PTV}_{\mathrm{F}}=\frac{\mathrm{TDI} * \text { Human bw } * \text { Percentage of PCDD/F intake with food }}{\text { Daily Fat Consumption } * \text { Transfer Factor }}$

[TDI]: pg/kg bw/d (EFSA 2018). [bw]: kg (EFSA 2012b).

[Percentage of PCDD/F intake with food]: without unit (decimal digit; Schwarz et al. 2014). [Daily fat consumption]:kg/d (Schwarz et al. 2012; Statista 2020).

[Transfer factor]: without unit (Quotient pg/g fat in diet/ $\mathrm{pg} / \mathrm{g}$ feed at steady state).

Equation 1: $\mathrm{PTV}_{\mathrm{F}}$ for feed for dairy cows in $\mathrm{pg} / \mathrm{kg}$ dry matter:

$\mathrm{PTV}_{\mathrm{F}}=\frac{0.14 * 70 * 0.3}{0.04 * 4.5}$

$\mathrm{PTV}_{\mathrm{F}}=16 \mathrm{pg} / \mathrm{kg}$ dry matter

Equation 2: $\mathrm{PTV}_{\mathrm{F}}$ for feed for laying hens in $\mathrm{pg} / \mathrm{kg}$ dry matter:

$\mathrm{PTV}_{\mathrm{F}}=\frac{0.14 * 70 * 0.06}{0.0038 * 1.9}$

$\mathrm{PTV}_{\mathrm{F}}=81 \mathrm{pg} / \mathrm{kg}$ dry matter

Equation 3: $\mathrm{PTV}_{\mathrm{F}}$ for feed for fattening pigs.

$\mathrm{PTV}_{\mathrm{F}}=\frac{0.14 * 70 * 0.05}{0.0113 * 2}$

$\mathrm{PTV}_{\mathrm{F}}=22 \mathrm{pg} / \mathrm{kg}$ dry matter.

Therefore, based on the assumptions above, the potential target values for feed for dairy cows, laying hens and fattening pigs are (Table 2):

Table 2 Potential target values for dioxins in feed

\begin{tabular}{lll}
\hline Feed & $\begin{array}{l}\text { Calculated potential target values in ng WHO-PCDD/F-TEQ/ } \\
\text { kg relative to a feed with a moisture content of 12\% }\end{array}$ & $\begin{array}{l}\text { Legal limit: maximum content in ng WHO-PCDD/F- } \\
\text { TEQ/kg relative to a feed with a moisture content of } \\
12 \%\end{array}$ \\
\hline $\begin{array}{l}\text { Feed materials of } \\
\text { plant origin }\end{array}$ & & 0.75 \\
Dairy cows & 0.014 \\
Laying hens & 0.072 \\
Fattening pigs & 0.019
\end{tabular}


$\mathrm{PTV}_{\text {F Dairy cow }}=0.016 \mathrm{ng}$ WHO-TEQ $/ \mathrm{kg}$ dry matter (equivalent to $14 \mathrm{pg} / \mathrm{kg}$ feed with $12 \%$ moisture).

$\mathrm{PTV}_{\mathrm{F} \text { laying hens }}=0.081 \mathrm{ng} \mathrm{WHO}-\mathrm{TEQ} / \mathrm{kg}$ dry matter (equivalent to $72 \mathrm{pg} / \mathrm{kg}$ feed with $12 \%$ moisture).

$\mathrm{PTV}_{\mathrm{F} \text { Fattening pigs }}=0.022 \mathrm{ng}$ WHO-TEQ $/ \mathrm{kg}$ dry matter (equivalent to $19 \mathrm{pg} / \mathrm{kg}$ feed with $12 \%$ moisture).

Taking into account the TWI of $2 \mathrm{pg}$ WHO-PCDD/FTEQ/kg bw for human exposure (by using the calculated "tolerable daily intake" ("TDI") of $0.14 \mathrm{pg}$ ), the derived PTV $_{\mathrm{F}}$ would be 10 to 54 times lower than the current legal maximum level of $0.75 \mathrm{ng}$ WHO-TEQ per $\mathrm{kg}$ feed $(12 \%$ moisture), according to Directive 2002/32/EC (2002).

In order to compare PTV $\mathrm{F}_{\mathrm{F}}$ DL-PCB-TEQ with PTV PCDD/F-TEQ, Eq. 1 was slightly adopted. We used TFs 7.47 (calculated from Lorenzi et al. 2020) and 5.32 (calculated from Hoogenboom et al. 2015) and the mean of both values (TF: 6.4; Table S1, S2 Supplementary Material) were included in our calculation (Eq. 1a). Percentage of DL-PCB exposure with dairy products is comparable to PCDD/F-TEQ and DL-PCB-TEQ (30\% vs. $27 \%$, resp.) (Schwarz et al. 2014). The same accounts for contribution of egg fat to the overall exposure to DL-PCB with food. A clearly higher contribution to overall food exposure to DL-PCB was only reported for pork (Schwarz et al. 2014). However, as no eligible studies were identified meeting our defined inclusion criteria, we did not calculate a PTV values for feed for laying hens and for feed for fattening pigs based on DL-PCB-TEQ.

Equation 1a: $\mathrm{PTV}_{\mathrm{F}}$ for feed for dairy cows in $\mathrm{pg} / \mathrm{kg}$ dry matter based on dl-PCB-TEQ:

$\mathrm{PTV}_{\mathrm{F}}=\frac{0.14 * 70 * 0.3}{0.04 * 6.4}$

$\mathrm{PTV}_{\mathrm{F}}=11 \mathrm{pg} / \mathrm{kg}$ dry matter (equivalent to $10 \mathrm{pg} / \mathrm{kg}$ feed with $12 \%$ moisture).

The potential target value for feed for dairy cows based on DL-PCB-TEQ would be slightly lower compared to the $\mathrm{PTV}_{\mathrm{F}}$ based on PCDD/F-TEQ.

\section{Discussion}

In our approach, we calculated potential target values of $\mathrm{PCDD} / \mathrm{F}$ in animal feed. Derived values should ensure safe levels in livestock products for human consumption. Here, we demonstrate the challenge to derivate potential target values for PCDD/F in feed for dairy cows, fattening pigs, and laying hens, considering the transfer from animal feed to livestock products for human consumption under the provision to not exceed the new TWI for PCDD/F (EFSA 2018). With the calculated low potential target values of the TWI (EFSA 2018), it was difficult to comply with the PCDD/F levels in the feed ration, because the calculated levels were 10-54 times lower as the current legal value $(0.75 \mathrm{ng} / \mathrm{kg}$ feed with $12 \%$ moisture)

\subsection{Analytical challenge}

According to Commission Regulation (EU) 2017/771, the limit of quantification (LOQ) for a confirmatory method should be approximately $1 / 5$ of the legal maximum level (Dir $2002 / 32 / E C$ ), to ensure the reliability of the performance results and the whole test method at low concentrations (EURL 2016). However, the potential target values calculated here by using the lowered TWI of $2 \mathrm{pg} / \mathrm{kg}$ bw and week, are 2.1-10.7 times below the currently required LOQ for PCDD/ Fs in feed raw materials and compound feed. Hence, lowering legal maximum levels in feed would also require improvement of analytical performance. Commission Regulation (EU) No 277/2012 already mentions the dependence of maximum levels on analytical performance. It states that setting lower maximum levels was not possible regarding the sensitivity of currently available methods of analysis at that time.

\subsection{Compliance with legal maximum levels in feed does not mean compliance with legal maximum levels in food}

Commission Regulation (EU) No 277/2012 further addresses the conflict regarding food of animal origin which exceeds the applicable maximum levels set by Commission Regulation (EC) No 1881/2006, even though maximum levels in feed comply with Directive 2002/32/EC. Lorenzi et al. (2020) selected the contamination level in order to comply with legal maximum levels for feed. The TEQ ratio between DL-PCB and PCDD/F was 3 to 1 in order to resemble the average TEQ ratio found in local forages. In their study, milk of exposed cows exceeded the maximum limit set for the sum of PCDD/Fs and DL-PCBs (5.5 pg TEQ/g fat) after one week of exposure whereas $\mathrm{WHO}_{2005}$-PCDD/F-TEQ alone never exceeded legal maximum levels but reached established action levels of $1.75 \mathrm{pg}$ TEQ/g fat) at day 21 of exposure. Hoogenboom et al. (2006) described exceedance of maximum levels in eggs in chickens fed with feed containing TEQ levels at or just above $(0.76 \mathrm{ng} / \mathrm{kg}$ feed $)$ the current EU maximum levels of $0.75 \mathrm{ng}$ TEQ/ $\mathrm{kg}$ feed. Our approach focusses on health-based guidance values instead of legal maximum levels in food. It demonstrates that potential target values are lower than current legal maximum levels for feed. In addition, maximum levels for food and feed are generally set based on occurrence data for feed and food and/ or on analytical practicality. Thus, a comparable approach could also be used to calculate PTV in food. Such approach must include dietary exposure assessment which would be an interesting point for further studies. 


\subsection{Variability of transfer factors}

Kinetics of the individual congeners are different resulting in various transfer rates from feed into food. Calculation based on total PCDD/F-TEQ in feed and the respective food (fat based) is possible if concentrations in food and feed are reported based on the sum of PCDD/F-TEQ. Regarding the literature values of $\mathrm{TF}$ or $\mathrm{BCF}$ on single congeners, our TFs are well within the range of reported values (e.g. Huwe and Smith 2005 and references cited therein). The most conservative approach would have been to use a TF of the toxicologically most relevant congeners with the highest transfer of toxicity. A recent meta-analysis shows mean transfer rates of $34.0 \pm 6.3 \%$ and $39.1 \pm 12.6 \%$ for TCDD from feed into milk and eggs, respectively (Amutova et al. 2021). For DL-PCB-126, the toxicologically most relevant DL-PCB congener, the transfer rates were $40 \pm 11.4 \%$ and $37.7 \pm 19.6 \%$ from feed into milk and eggs, respectively. In our calculation, we used TFs which accounted for accumulation of PCDD/Fs and DL-PCBs in animal products. If transfer rates are used, the equations must be adopted.

We calculated TFs and exemplarily considered only one livestock product, milk, egg, and pork, respectively. In dairy cows we only looked at the transfer from feed into milk, whereas transfer into meat was disregarded. As the liver also accumulates PCDD/F, there is an uncertainty regarding congener specific accumulation in fat, liver or kidney (e.g. Huwe and Smith 2005) and with that also the consumer's safety regarding liver or kidney consumption. However, accumulation in liver of cows is less important compared to e.g. in sheep (EFSA 2011; Fernandes et al. 2011). Furthermore, most important for human exposure is the consumption of milk and milk products. Hence, this uncertainty may lead to a slight overestimation but is justifiable regarding the theoretical and simplified approach of our calculation. A refinement could be achieved by modelling e.g. mass balances.

Comparable or slightly higher values would be achieved if $\mathrm{PTV}_{\mathrm{F}}$ are calculated based on the sum of PCDD/F and DL-PCB-TEQs. ${ }^{3}$

Various definitions and values are reported for the transfer from animal feed to livestock products for human consumption. Based on TF or BCF values summarized by Huwe and

\footnotetext{
${ }^{3}$ Using a mean TF of 5.3 for $\mathrm{WHO}_{2005}$-PCDD/F-PCB-TEQ based on Lorenzi et al. (2020; TF =7) and TF 3.7 (Hoogenboom et al. 2015 ;), the tolerable "daily" intake of $0.28 \mathrm{pg} / \mathrm{kg} \mathrm{bw*d}$ with food is still 0.3 (TWI of $2 \mathrm{pg} / \mathrm{kg}$ bw*week daily; contribution of exposure to $\mathrm{WHO}_{2005}$-PCDD/F-PCB-TEQ). The resulting potential target value would approx. be twice as high (28 pg $\mathrm{WHO}_{2005}$-PCDD/F-PCB-TEQ/ $\mathrm{kg}$ dry matter). As kinetics of PCDD/F congeners and dl-PCB congeners are different and the literature predominantly assessed higher exposure to dl-PCB, a separate calculation for PCDD/F-TEQ and dlPCB-TEQ appears more appropriate.
}

Smith (2005) for single PCDD/F congeners, values appear to depend on several factors, e.g. feed material, concentrations in feed, study duration etc. The range for the toxicologically most relevant congeners $(2,3,7,8$-TCDD and 1, 2, 3, 7, 8-PeCDD) has been reported to be between 1.12 and 8.99 (mineral supplement), with most values being between 4 and 8 . The values are comparable to the TF we used in our calculation. For example, an increase of TFs (e.g. twofold) would result in a $\mathrm{PTV}_{\mathrm{F}}$ half as high as the reported ones and vice versa.

\subsection{Steady state conditions in transfer studies}

Concentrations in animal products were chosen if steady state conditions were reported (Lorenzi et al. 2020; Hoogenboom et al. 2015). Those were 49 and 29 days of exposure for transfer into milk, respectively. The transfer from feed into eggs took 178 days of exposure (Stephens et al. 1995), and a 12-week exposure period (study duration 18 weeks) for the transfer from feed into pork of fattening pigs (Spitaler et al. 2005). Normally, feed intake at steady state applies to adult animals with good productivity, except for fattening pigs whose daily feed consumption steadily increases from app. $1 \mathrm{~kg}$ to $3 \mathrm{~kg}$ in accordance to its live weight gain of up to $800 \mathrm{~g}$ per day until reaching $100-120 \mathrm{~kg}$ during the fattening period (Jeroch et al. 2008). Hence, achievement of stable conditions is difficult to achieve in fattening pigs (Amutova et al. 2021). If exposure periods are not sufficiently long to achieve steady state conditions, accumulation of PCDD/F would be underestimated. For instance, Hoogenboom et al. (2015) reported "nearly steady state conditions" whereas Lorenzi et al. (2020) reported steady state conditions. We used the mean of TFs in our calculation which may lead to a slightly underestimation if steady state conditions in the study by Hoogenboom et al. was not achieved (TF were lower than in study by Lorenzi et al. 2020). Feed intake is not expected to have a big influence at steady state. The daily fat production and animals body weight were not directly calculated, but indirectly through the calculation of fat concentration in feed and milk, egg, and pork meat, respectively. Calculation of TF at steady state conditions in the fat of the regarded livestock product implies that both feed consumption and fat production in animals have no impact on $\mathrm{PCDD} / \mathrm{F}$ concentration in fat.

\subsection{Variability in PCDD/F and DL-PCB congeners transfer}

There is a discrepancy between the percentages of overall $\mathrm{PCDD} / \mathrm{F}$ contribution of congeners in food and feed compared to the contribution of congeners to the overall $\mathrm{PCDD} / \mathrm{F}$ toxicity. Data shows that 1, 2, 3, 4, 6, 7, 8, 9-OCDD; 1, 2, $3,4,7,8,9-\mathrm{HpCDD}$; and OCDF were quantitatively the 
dominant congeners in feed and food of animal origin. However, they were the least relevant to toxicity, due to their low WHO-TEF value and their low transfer rates (e.g. Fries et al. 1999; Malisch 2000; Brambilla et al. 2008; EFSA 2012a; EFSA 2018). Recently, Lorenzi et al. (2020) confirmed in a controlled feeding study that OCDD characterized the milk profile in untreated animals, or in treated animals before and during the clearance phase. Around $30 \%$ of PCDD/F in milk derived from unexposed cows, compared to approx. $4 \%$ at steady state in milk derived from exposed cows. OCDD, $\mathrm{HpCDD}$, and 2, 3, 4, 7, 8-PeCDF accounted for around 52\% of total PCDD/F in milk. In contrast, 2, 3, 7, 8-TCDD contributed to max. $0.5 \%$ of $\mathrm{PCDD} / \mathrm{F}$ concentration in milk in unexposed cows but was responsible for around $10 \%$ of overall toxicity. In exposed cows, contribution increased from approx. 0-2.4\% (day 49, end of exposure phase). However, calculation of TF from PCDD/F-TEQ in food and feed considers the different contribution of congeners to $\mathrm{PCDD} / \mathrm{F}$ toxicity.

\subsection{Variable exposure of PCDD/F feed on livestock}

Generally, it could be assumed that livestock is not long time exposed to feed with homogenously levels of dioxins. Thus, realistic exposure would include high and low exposure scenarios. On the other hand, we showed that derived $\mathrm{PTV}_{\mathrm{F}}$ are low and in the magnitude of background levels for feed. For example, median levels of PCDD/F-TEQ (17 congeners) in 206 samples of feed (roughage, fresh forage - fresh grass etc.-compound feed) were $0.03 \mathrm{ng} / \mathrm{kg}(88 \% \mathrm{DM})$ and clearly below maximum level of $0.75 \mathrm{ng} / \mathrm{kg}$. Our derived $\mathrm{PTV}_{\mathrm{F}}$ of $0.016-0.081 \mathrm{ng} \mathrm{PCDD} / \mathrm{F} \mathrm{WHO}_{2005}-\mathrm{TEQ} / \mathrm{kg} \mathrm{DM}$ are comparable to mean concentrations of $0.03-0.09 \mathrm{ng}$ $\mathrm{WHO}_{2005}-\mathrm{TEQ} / \mathrm{kg}$ DM (median of all feed samples: $0.02 \mathrm{ng} /$ $\mathrm{kg}$ WHO-TEQ $/ \mathrm{kg} 88 \% \mathrm{DM}$ ) in which none of the samples exceeded legal ML (Federal Ministry of Food and Agriculture 2009). Mueller et al. (2021) found very low concentrations of PCDD/F-TEQ single congeners in feed from grassland (closely to or below LOQ; LOQ: not reported). Mean concentration of PCDD/F- $\mathrm{WHO}_{2005}$-TEQ in grassland feed (unwashed) was $0.09 \mathrm{ng} / \mathrm{kg}$ DM (range: 0.053 to $0.191 \mathrm{ng} /$ $\mathrm{kg} \mathrm{DM}$ ). Concentrations of single congeners were very low, often at or below LOQ (LOQs were not reported in the publication). Current background levels for roughage and compound feed in German monitoring data were between 0.01 and $0.008 \mathrm{ng} \mathrm{WHO-PCDD/F-TEQ/kg} 88 \% \mathrm{DM}$, respectively (CVUA Freiburg 2019). As described for feed, MLs for food items are generally set based on occurrence data (e.g. P95) rather than on data on toxicity. If livestock is exposed to $\mathrm{PCDD} / \mathrm{F}$ in feed compliant with derived $\mathrm{PTV}_{\mathrm{F}}$, exceedance of maximum levels in food are not expected. Transfer studies showed that PCDD/F levels in milk, eggs and pork meat may exceed MLs or action levels if content in feeds is below or at the current ML for feed (roughage, compound feed) of $0.75 \mathrm{ng}$ TEQ $/ \mathrm{kg}$ (Hoogenboom et al. 2015; Lorenzi et al. 2020; Spitaler et al. 2005).

\subsection{Uncertainty in the derived TWI for PCDD/F + DL-PCB-TEQ}

Finally, there are also uncertainties concerning the TWI of $2 \mathrm{pg} / \mathrm{kg} \mathrm{bw} /$ week due to the contribution of exposure of congeners to PCDD/F and DL-PCB TEQ, especially of PCB 126. The latter has the highest toxicity potency $\left(\mathrm{WHO}_{2005}-\mathrm{TEF}\right.$ : $0.1)$ regarding DL-PCBs. TEF factors will be re-assessed by an WHO expert group following a peer review of the relative effect potencies of PCDDs, PCDFs and PCBs (EFSA $2021^{4}$ ). If this assessment results in different TEFs it will influence overall assessment of dioxin exposure and toxicity. For instance, Lorenzi et al. (2020) demonstrated an overall contribution of PCB 126 to DL-PCB TEQ between 74 and 91\% in milk of exposed and unexposed cows, respectively. $\mathrm{PCB}$ 126 is the DL-PCB contributing most to the current intake of PCDD/F and DL-PCB-TEQ with food (EFSA 2018). If TEF of PCB 126 would result in a lower value than the pattern of contribution to overall DL-PCB toxicity (and also PCDD/F+DLPCB TEQ) may change significantly.

\subsection{Other uncertainties}

In our approach, an underestimation can occur if $\mathrm{PCDD} / \mathrm{F}$ transfer from soil to livestock is disregarded for animals in free-range production, which applies in particular to poultry and grazing cattle (e.g. Schwind et al. 2010). Some authors included concentrations of soil and feed in their studies (e.g. Hoogenboom et al. 2015). In addition to feed, livestock in free-range husbandry can also take up PCDD/F via grazing or soil ingestion (Schoeters and Hoogenboom 2006). In particular, the intake of contaminated soil leads to a significant accumulation in animals and transfer to food of animal origin (Schulz et al. 2005). Any additional intake of PCDD/F through sources other than feed will lead to lower potential target values for feed, as calculated.

Moreover, there are no current studies on PCDD/F and PCB levels in feed of different feed categories such as compound feed, roughage and forages. The last national survey of these contaminants in feed and food of animal origin dates back to 2009 in Germany (Federal Ministry of Food and Agriculture 2009). Therefore, we propose to perform a new feed survey, because current contamination of feed with PCDD/Fs and PCBs might have changed over time. In addition, analytical performance could also be improved since the most recent publication of maximum levels in feed.

\footnotetext{
${ }^{4}$ https://www.efsa.europa.eu/en/call/peer-review-database-relativeeffect-potencies-pcdds-pcdfs-and-pcbs-and-preparing-review-use, Accessed 20.10.2021.
} 
Table 3 Sources and directions of uncertainties of $\mathrm{PTV}_{\mathrm{F}}$ derivation

\begin{tabular}{ll}
\hline Source of uncertainty & Direction \\
\hline Calculation with body weights for adults & PTV $\downarrow$-Underestimation (regarding e.g. children) \\
Transfer for only one food item considered & PTV $\uparrow$-Overestimation \\
Variation in TF: TF factor lower & PTV $\uparrow$-Overestimation (the higher TF the lower PTV would be) \\
Variation in TF: TF factor higher & PTV $\downarrow$-Underestimation \\
Very low concentration of PCDD/F; dl-PCB in feed & PTV $\uparrow$-Overestimation (due to e.g. analytical uncertainty) \\
Exposure period too short to achieve steady state & PTV $\downarrow$-Underestimation \\
Equal contribution of PCDD/F and dl-PCB to exposure & PTV $\uparrow$ Overestimation regarding PCDD/F, PTV $\downarrow-$ Underesti- \\
& mation regarding dl-PCB
\end{tabular}

$\uparrow$ : overestimation; $\downarrow$ : underestimation

For derivation of potential target values in feed, equal proportions of PCDD/Fs and PCBs in feed were used for calculation. However, a 3:1 ratio for DL-PCB and PCDD/Fs in feed and food is more realistic (e.g. Lorenzi et al. 2020; Schwarz et al. 2014; Hoogenboom et al. 2004; Huwe and Smith 2005). Nevertheless, there would be in the same magnitude if the calculation was performed including DL-PCB PTV $\mathrm{F}_{\mathrm{F}}$ in dairy cow feed for PCDD/F + DL-PCB-WHO 2005 TEQ.

We based our calculation of $\mathrm{PTV}_{\mathrm{F}}$ on adult consumers. However, children are likely to be more vulnerable to PCDD/F+ DL-PCB exposure. The TWI by EFSA was based on serum concentration in 5-year old boys after a modelled external exposure in order to derive the TWI. For this reason, the TWI also covers exposure to children. If we use a body weight of $12 \mathrm{~kg}$ for children as a default value for children aged of 1-3 years (EFSA 2012b), in our calculations PTV $_{F}$ would be lower than in $70 \mathrm{~kg}$ adults (approx. by factor 6). Thus, our derived PTV $_{\mathrm{F}}$ may underestimate the risk of PCDD/F exposure in children. Sources and directions of uncertainties of $\mathrm{PTV}_{\mathrm{F}}$ derivation are shown in Table 3.

\section{Conclusions}

In conclusion, the described approach could contribute to the discussion about the need for an integrative approach considering derivation of maximum levels in feed and food, and thereby also regarding risk assessment for human health. Livestock has an important role along the food chain from farm to fork. Levels of contaminants in feed can accumulate in animals and their products reach consumers at the end of the food chain. Several steps along the food chain should be regarded when setting maximum levels for feed because transfer from feed into animals and further into food for human consumption are relevant with regard to consumer's safety, especially for lipophilic contaminants. This approach might serve as a management tool to better integrate the setting of maximum levels in feed and food with health based guidance values for human risk assessment. Our $\mathrm{PTV}_{\mathrm{F}}$ should be regarded as "target values" rather than proposals of MLs for feed. This could be compromised by aiming for avoidance of feed and food waste and by analytical practicality. However, levels in feed might have been decreased during the last ten years or so. Thus, a new feed survey would help to reflect the current situation regarding concentrations of $\mathrm{PCDD} / \mathrm{F}$ and DL-PCB in feed.

Supplementary Information The online version contains supplementary material available at https://doi.org/10.1007/s00003-021-01350-0.

Authors contributions MJAC: performed research, analyzed data, wrote the paper, JK, BW: designed the study, wrote the paper.

Fundings Open Access funding enabled and organized by Projekt DEAL. Maria José Abud Clariget received a "Werner Baltes Fellowship" at the German Federal Institute for Risk Assessment (BfR).

Open Access This article is licensed under a Creative Commons Attribution 4.0 International License, which permits use, sharing, adaptation, distribution and reproduction in any medium or format, as long as you give appropriate credit to the original author(s) and the source, provide a link to the Creative Commons licence, and indicate if changes were made. The images or other third party material in this article are included in the article's Creative Commons licence, unless indicated otherwise in a credit line to the material. If material is not included in the article's Creative Commons licence and your intended use is not permitted by statutory regulation or exceeds the permitted use, you will need to obtain permission directly from the copyright holder. To view a copy of this licence, visit http://creativecommons.org/licenses/by/4.0/.

\section{References}

Amutova F, Delannoy M, Baubekova A, Konuspayeva G, Jurijanz S (2021) Transfer of persistent organic pollutants in food of animal origin-meta-analysis of published data. Chemosphere 262:128351. https://doi.org/10.1016/j.chemosphere.2020.128351

Brambilla G, Fochi I, Falce M, De Filippis SP, Ubaldi A, di Domenico A (2008) PCDD and PCDF depletion in milk from dairy cows according to the herd metabolic scenario. Chemosphere 73:S216-S219 
Commission Regulation (EC) No 1881/2006 of 19 December 2006 setting maximum levels for certain contaminants in foodstuffs. OJ L 364, 20.12.2006, p. 5-24 (as amended)

Commission Regulation (EU) No 1259/2011 of 2 December 2011 amending Regulation (EC) No 1881/2006 as regards maximum levels for dioxins, dioxin-like PCBs and non dioxin-like PCBs in foodstuffs. OJ L 320, 3.12.2011, p. 18-23

Commission Regulation (EU) No 277/2012 of 28 March 2012 amending Annexes I and II to Directive 2002/32/EC of the European Parliament and of the Council as regards maximum levels and action thresholds for dioxins and polychlorinated biphenyls. OJ L 91, p. 1-17

Commission Regulation (EU) 2017/771 of 3 May 2017 amending Regulation (EC) No 152/2009 as regards the methods for the determination of the levels of dioxins and polychlorinated biphenyls. OJ L $115,4.5 .2017$, p. 22-42

CVUA Freiburg (2019) Dioxine und polychlorierte Biphenyle in Lebensmitteln und Futtermitteln-Untersuchungsergebnisse 2019. Jahresbericht 2019. https://www.cvua-freiburg.de/uploa ddoc/cvuafr/dioxine_pcb_jahresbilanz_2019_ausfuehrlich.pdf (last Accessed on 6th October 2021)

Directive 2002/32/EC of the European Parliament and of the Council of 7 May 2002 on undesirable substances in animal feed. OJ L $140,1-28$

European Food Safety Authority (EFSA) (2012a) Scientific report of EFSA. Update of the monitoring of levels of dioxins and PCBs in food and feed. EFSA J 10(7):2832

European Food Safety Authority (EFSA) (2012b) EFSA scientific committee; guidance on selected default values to be used by the EFSA Scientific Committee, Scientific Panels and Units in the absence of actual measured data. EFSA J 10:2579

European Food Safety Authority (EFSA)-EFSA Panel on contaminants in the food chain (2011) Scientific Opinion on the risk of public health related to the presence of high levels of dioxins and dioxin-like PCBs in liver from sheep and deer. EFSA J 9(7):2297

European Food Safety Authority (EFSA) EFSA Panel on contaminants in the food chain (2018) Scientific Opinion of EFSA. Risk for animal and human health related to the presence of dioxins and dioxin-like PCBs in feed and food. EFSA J 16 (11): 5333

European Union Reference Laboratory (EURL) (2016) Guidance document on the estimation of LOD and LOQ for measurements in the field of contaminants in feed and food. In: Wenzl T, Haedrich J, Schaechtele A, Robouch P, Stroka J (eds) Members of the networks of National Reference Laboratories for heavy metals, PAHs, Mycotoxins and members of the working group of the network of the EURL and NRLs for dioxins and PCBs in feed and food for measurement uncertainty in PCDD/F and PCB analysis, pp 52

Federal Ministry of Food and Agriculture (Bundesministerium für Ernährung und Landwirtschaft) (2009): former name: Federal Ministry of Food, Agriculture and Consumer Protection (Bundesministerium für Ernährung, Landwirtschaft und Verbraucherschutz: Statuserhebung zu Dioxinen und PCB in Futter- und vom Tier stammenden Lebensmitteln. Schriftenreihe des Bundesministeriums für Ernährung, Landwirtschaft und Verbraucherschutz. Reihe A: Angewandte Wissenschaft, Heft 522. Filderstadt: Verlagsgesellschaft W.E. Weinmann e.K., 186 pp

Fernandes AR, Foxall C, Lovett A, Rose M, Dowding A (2011) The assimilation of dioxins and PCBs in conventionally reared farm animals: occurrence and biotransfer factors. Chemosphere $83: 815-822$

Fries GF (1995) A review of the significance of animal food products as potential pathways of human exposures to dioxins. J Anim Sci 73:1639-1650

Fries GF, Paustenbach DJ, Mather DB, Luksemburg WJ (1999) A congener specific evaluation of transfer of chlorinated Dibenzo- $p$-dioxins and dibenzofurans to milk of cows following ingestion of pentachlorophenol-treated wood. Environ Sci Technol 33:1165-1170

Hoogenboom RLAP, Kan CA, Bovee TFH, van der Weg G, Onstenk C, Traag WA (2004) Residues of dioxins and PCBs in fat of growing pigs and broilers fed contaminated feed. Chemosphere 57:35-42

Hoogenboom RL, Zeilmaker M, Traag W, Kan K, van Eijkeren J (2006) Carry-over of dioxins and PCBs from feed and soil to eggs at low contamination levels; Influence of mycotoxin binders on the carry-over from feed to eggs. Food Addit Contam 23:518-527

Hoogenboom RLAP, Klop A, Herbes R, van Eijkeren JCH, Zeilmaker MJ, van Vuuren AM, Traag WA (2015) Carry-over of polychlorinated dibenzo-p-dioxins and dibenzofurans (PCDD/Fs) and polychlorinated biphenyls (PCBs) in dairy cows fed smoke contaminated maize silage or sugar beet pulp. Chemosphere 137:214-220

Huwe JK, Smith DJ (2005) Laboratory and on-farm studies on the bioaccumulation and elimination of dioxins from a contaminated mineral supplement fed to dairy cows. J Agric Food Chem 53:2362-2370

Jeroch H, Drochner W, Simon O (2008) Chapter: 1.2.7 Fütterung der Mastschweine, Page 346. In: Ernährung landwirtschaftlicher Nutztiere- - Ernährungsphysiologie, Futtermittelkunde, Fütterung. 2. Auflage. Eugen Ulmer Stuttgart. ISBN 978-3-8252-8180-9

Lorber M, Fries GF, Winters D, Ferrario J, Byrne C (2000) A study of the mass balance of dioxins and furans in lactating cows in background conditions. Part 2: mass balance and bioconcentration factors. Organohal Compd 46:326-329

Lorenzi V, Angelone B, Ferretto E, Galli A, Tonoli M, Donati M, Fusi F, Zanardi G, Ghidini S, Bertocchi L (2020) PCDD/Fs, DL-PCBs, and NDL-PCBs in dairy cows: carryover in milk from a controlled feeding study. J Agric Food Chem 68:2201-2213

Malisch R (2000) Increase of the PCDD/F contamination of milk, butter and meat samples by use of contaminated citrus pulp. Chemosphere 40:1041-1053

Mueller I, Lindner A, Frenzel T, Steinhöfel O. Dioxintransfer BodenGrünland-Rind. Schriftenreihe, Heft 2/2019 des Landesamts für Umwelt, Landwirtschaft und Geologie im Freistaat Sachsen: 1. 58

Schoeters G, Hoogenboom R (2006) Contamination of free-range chicken eggs with dioxins and dioxin-like polychlorinated biphenyls. Mol Nutr Food Res 50:908-914

Schulz AJ, Wiesmüller T, Appuhn H, Stehr D, Severin K, Landmann D, Kamphues J (2005) Dioxin concentration in milk and tissues of cows and sheep related to feed and soil contamination. J Anim Physiol Anim Nutr (Berl) 89:72-78

Schwarz MA, Lindtner O, Blume K, Heinemeyer G, Schneider K (2014) Dioxin and DL-PCB exposure from food: the German LExUKon project. Food Add Contam Part A 31:688-702

Schwarz MA, Schneider K (2012) Studie zur Berücksichtigung der Daten der Statuserhebung des BMELV bei der Expositionsschätzung für PCDD/F und dl-PCB - FK 3 1329-47-im Auftrag des Bundesinstituts für Risikobewertung FoBiG, Forschungs- und Beratungsinstitut Gefahrstoffe GmbH: 1-57

Schwind KH, Daenicke S, Jira W (2010) Survey of dioxins, dioxin-like PCBs and marker PCBs in German feeds of plant origion. J Verbr Lebensm 5:413-420

Spitaler M, Iben C, Tausch H (2005) Dioxin residues in the edible tissue of finishing pigs after dioxin feeding. J Anim Physiol Anim Nutr 89:65-71

Statista (2020) Pro-Kopf-Konsum von Fleisch in Deutschland nach Art in den Jahren 2017 bis 2019. Online available at https://de.stati sta.com/statistik/daten/studie/311479/umfrage/pro-kopf-konsumvon-fleisch-in-deutschland-nach-arten/ (Accessed 21 July 2020)

Stephens RD, Petreas MX, Hayward DG (1995) Biotransfer and bioaccumulation of dioxins and furans from soil: chickens as a model for foraging animals. Sci Total Environ 175:253-273

Travis CC, Hattemer-Frey HA (1991) Human exposure to dioxin. Sci Total Environ 104:97-127 
Van den Berg M, Birnbaum L, Bosveld ATC, Brunstr€om B, Cook P, Feeley M, Giesy J, Hanberg A, Hasegawa R, Kennedy SW, Kubiak T, Larsen JC, van Leeuwen FXR, Liem AKD, Nolt C, Peterson RE, Poellinger L, Safe S, Schrenk D, Tillitt D, Tysklind M, Younes M, Wærn F, Zacharewski T (1998) Toxic equivalency factors (TEFs) for PCBs, PCDDs, PCDFs for humans and wildlife. Environ Health Persp 106:775-792

Van den Berg M, Birnbaum LS, Denison M, de Vito M, Farland W, Feeley M, Fiedler H, Hakansson H, Hanberg A, Haws L, Rose M, Safe S, Schrenk D, Tohyama C, Tritscher A, Tuomisto J, Tysklind Walker N, Peterson RE (2006) The 2005 World Health Organization re-evaluation of human and mammalian toxic equivalency factors for dioxins and dioxin-like compounds. Toxicol Sci 93:223-241

Verein Deutscher Ingenieure (VDI, Association of German Engineers) (2005) Maximale Immissions-Werte-Maximale ImmissionsWerte für Dioxine zum Schutz der landwirtschaftlichen Nutztiere-maximum immission values for dioxins to protect farm animals. VDI 2310 Blatt/Part 46:1-11
Verein Deutscher Ingenieure (VDI, Association of German Engineers) (2019) Maximale Immissions-Werte - Maximale ImmissionsWerte für Dioxine zum Schutz der landwirtschaftlichen Nutztiere-Maximum immission values for dioxins to protect farm animals. VDI 2310 Blatt/Part 46:1-14

Windal I, Vandevijvere S, Maleki M, Goscinny S, Vinkx C, Focant JF, Eppe G, Hanot V, Van Loco J (2010) Dietary intake of PCDD/Fs and dioxin-like PCBs of the Belgian population. Chemosphere 79:334-340

World Health Organization (WHO) (2010) Preventing disease through healthy environments. Exposure to dioxins and dioxin-like substances: a major public health concern. Public Health and Environment. World Health Organization, Geneva 27, Switzerland, 6 pp

Publisher's Note Springer Nature remains neutral with regard to jurisdictional claims in published maps and institutional affiliations. 